\title{
Growth, Laser Raman, Thermal, Edax and Photoluminescence Studies of Pure and Calcium Doped Zinc Hydrogen Phosphate Crystals Using Single Diffusion Technique
}

\author{
T. Jayaprakash ${ }^{\mathrm{a},{ }^{*}, \text { P. Kalugasalam }}{ }^{\mathrm{b}}$ and S.M. Deepa ${ }^{\mathrm{c}}$ \\ ${ }^{a}$ Department of Physics, Nehru Institute of Technology, Coimbatore, Tamilnadu, India \\ ${ }^{b}$ Department of Physics, Tamilnadu College of Engineering, Coimbatore, Tamilnadu, India \\ ${ }^{c}$ Deartment of ECE, Nehru Institute of Engineering and Technology, Tamilnadu, India
}

\begin{abstract}
Growth aspects of pure and Calcium doped Zinc hydrogen phosphate single crystals from silica gel by the process of single diffusion technique are discussed. Crystals with different morphologies and effect on various parameters like gel $\mathrm{pH}$, and gel ageing, gel density and concentration of reactants on the growth of pure and Calcium doped $\mathrm{ZnHPO}_{4}$ crystals were studied. Laser Raman spectra of the pure and Calcium doped $\mathrm{ZnHPO}_{4}$ crystals are recorded and the vibrational assignments have been made with possible explanations. Thermo gravimetrical analysis is undertaken to study the thermal stability of the grown crystals. The photoluminescence measurement shows that the material is suitable for photonic devices. The crystals grown were characterized by Laser Raman spectrum, TG/DTA, EDAX and Photoluminescence.
\end{abstract}

Received on 29-01-2017 Accepted on 01-09-2017 Published on 05-10-2017

Keywords: Gel technique, TG/DTA, EDAX, Laser

Raman, and

Photoluminescence.

\section{INTRODUCTION}

Single crystals are the backbone of the modern technological revolution. The art of growing crystals in silica gel medium is not new for researchers because of its simplicity, low cost and crystals can be grown at room temperature. But the challenges and opportunities in understanding the growth structure and features of grown crystal remain there. Crystals of great interest from both solid state sciences as well as technological point of view has been reported by many researchers using gel method. The principle relies on the slow migration of crystal constituents (ions) through silica gel so that a very slow reaction occurs with the formation of a sparingly soluble compound. When the concentration of this compound exceeds the solubility limits, crystals will be formed, the main function of the silica gel being to control the flow of reacting ions [1-5]. Doped crystals growth has scarcely been studied by employing the gel technique [6-7] and the field is in an early stage of development with many opportunities to create new species. Most of the phosphate compounds are in soluble in water and decompose before melting. Hence single crystals of such type of compounds

"Department of Physics, Nehru Institute of Technology, Coimbatore, Tamilnadu, India; Tel: +91 9843121361; E-mail: ilandirayan_jp@yahoo.co.in cannot be grown by either slow evaporation or melt technique. In this situation single diffusion technique is the appropriate one for their growth. In conventional growth, pure $\mathrm{ZnHPO}_{4}$ crystals were accomplished at $40^{\circ} \mathrm{C}$ in a constant temperature bath have been already reported [8]. In this present work, we have attempted to grow pure and calcium doped $\mathrm{ZnHPO}_{4}$ crystals by single diffusion technique at room temperature [9-13]. The purpose of the present article is to report for the first time the growth of pure and calcium doped single crystals in silica gel medium by using single diffusion technique at room temperature. These crystals have identified and characterized by TG/DTA, EDAX, LASER RAMAN, and PL. The results of these observations are described and discussed.

\section{EXPERIMENTAL}

\subsection{Materials}

All reagents used were of analytical grade purity and were produced from Merck Chemical Reagent Co. Ltd. India.

\subsection{Preparation Technique}

Pure and Calcium doped Zinc Hydrogen Phosphate in the form of a single crystal is accomplished by using single 
Table 1: $\quad \mathrm{ZnHPO}_{4}$ Crystal Growth Procedure

\begin{tabular}{|c|c|c|c|c|c|c|c|}
\hline $\begin{array}{l}\text { Silica Gel } \\
\text { Density } \\
\text { gm/cc }\end{array}$ & $\begin{array}{c}\mathrm{H}_{3} \mathrm{PO}_{4} \text { Acid } \\
\text { concentration in } \\
\text { Normality }\end{array}$ & $\mathrm{pH}$ & $\begin{array}{c}\text { Gel } \\
\text { ageing }\end{array}$ & $\begin{array}{c}\text { Supernatant } \\
\text { concentration } \\
\left(\mathrm{Zn}\left(\mathrm{NO}_{3}\right)_{2} \cdot 6 \mathrm{H}_{2} \mathrm{O} \text { in } \mathrm{M}\right.\end{array}$ & $\begin{array}{l}\text { Nucleation } \\
\text { Started }\end{array}$ & $\begin{array}{l}\text { Growth } \\
\text { Period }\end{array}$ & $\begin{array}{c}\text { Nature of Crystal observed and } \\
\text { Harvested crystal size }\end{array}$ \\
\hline 1.04 & $1 \mathrm{~N}$ & $\begin{array}{l}5 \\
6 \\
7\end{array}$ & $\begin{array}{l}144 \mathrm{hrs} \\
36 \mathrm{hrs} \\
4 \mathrm{hrs}\end{array}$ & $1 \mathrm{M}$ & $\begin{array}{l}12 \mathrm{hrs} \\
24 \mathrm{hrs} \\
38 \mathrm{hrs}\end{array}$ & 244 days & $\begin{array}{c}\mathrm{pH}=5-\text { very tiny } X \text { shape } \\
\mathrm{pH}=6-\text { few } X \text { shape \& platelet } \\
\mathrm{pH}=7-3 \times 4 \mathrm{~mm} \text { Xshape single }\end{array}$ \\
\hline
\end{tabular}

Table 2: Calcium Doped $\mathrm{ZnHPO}_{4}$ Crystal Growth Procedure

\begin{tabular}{|c|c|c|c|c|c|c|c|}
\hline $\begin{array}{l}\text { Silica Gel } \\
\text { Density } \\
\text { gm/cc }\end{array}$ & $\begin{array}{c}\mathrm{H}_{3} \mathrm{PO}_{4} \text { Acid } \\
\text { concentration in } \\
\text { Normality }\end{array}$ & $p^{H}$ & $\begin{array}{l}\text { Gel } \\
\text { ageing }\end{array}$ & $\begin{array}{c}\text { Supernatant concentration } \\
\left(\mathrm{Zn}\left(\mathrm{NO}_{3}\right)_{2} \cdot 6 \mathrm{H}_{2} \mathrm{O}+\right. \\
\left.\mathrm{Ca}\left(\mathrm{NO}_{3}\right)_{2} \cdot 4 \mathrm{H}_{2} \mathrm{O}\right) \text { in } \mathrm{M}\end{array}$ & $\begin{array}{l}\text { Nucleation } \\
\text { Started }\end{array}$ & $\begin{array}{l}\text { Growth } \\
\text { Period }\end{array}$ & $\begin{array}{c}\text { Nature of Crystal observed and } \\
\text { Harvested crystal size }\end{array}$ \\
\hline 1.04 & $1 \mathrm{~N}$ & $\begin{array}{l}5 \\
6 \\
7\end{array}$ & $\begin{array}{l}144 \mathrm{hrs} \\
36 \mathrm{hrs} \\
4 \mathrm{hrs}\end{array}$ & $1: 1$ ratio & $\begin{array}{l}8 \mathrm{hrs} \\
12 \mathrm{hrs} \\
24 \mathrm{hrs}\end{array}$ & 244 days & $\begin{array}{c}\mathrm{pH}=5-\text { poly crystals } \\
\mathrm{pH}=6-\text { good needle } \& \text { platelet } \\
\mathrm{pH}=7-2 \times 3 \mathrm{~mm} \text { single } \\
\text { Lissegang rings form }\end{array}$ \\
\hline
\end{tabular}

diffusion technique at room temperature. The silica gel was prepared by adding $284.20 \mathrm{~g}$ of Sodium Meta Silicate $\left(\mathrm{Na}_{2} \mathrm{SiO}_{3} .9 \mathrm{H}_{2} \mathrm{O}\right)$ to 1 liter of double de-mineralized water, so as to have a gel concentration of $1 \mathrm{M}$. The density of the solution was determined by the specific gravity bottle method. The gel density values of $1.03 \mathrm{~g} / \mathrm{cc}, 1.04 \mathrm{~g} / \mathrm{cc} \& 1.05 \mathrm{~g} / \mathrm{cc}$ measurement was done very accurately since it has considerable influence on the gelation process and quality of the crystal. The $\mathrm{pH}$ of the silica gel was adjusted between the values of 5-7 by mixing the orthophosphoric acid $\left(\mathrm{H}_{3} \mathrm{PO}_{4}\right)$ and stock solutions in various proportions. Continuous stirring is needed to avoid excessive local ion concentration, which may cause premature local gelling and make a final solution inhomogeneous. The desired value of the $\mathrm{pH}$ of the solution was transferred to several single glass test tubes of length 20 $\mathrm{cm}$ and diameter $2.5 \mathrm{~cm}$. After the gel ageing, the supernatant solutions of $\mathrm{Zn}\left(\mathrm{NO}_{3}\right)_{2} .6 \mathrm{H}_{2} \mathrm{O}$ (Zinc Nitrate - AR Grade) and $\mathrm{Ca}\left(\mathrm{NO}_{3}\right)_{2} .4 \mathrm{H}_{2} \mathrm{O}$ (Calcium Nitrate - AR Grade) at a required mole solution was slowly added along the walls of the test tubes over the set goals and tightly closed to prevent evaporation. The following expected reaction takes place in the growth columns and growth procedure is listed in the Tables $1 \& 2$.

$$
\begin{aligned}
& \mathrm{Zn}\left(\mathrm{NO}_{3}\right)_{2} \cdot 6 \mathrm{H}_{2} \mathrm{O}+\mathrm{H}_{3} \mathrm{PO}_{4} \rightarrow \mathrm{ZnHPO}_{4}+2 \mathrm{HNO}_{3}+6 \mathrm{H}_{2} \mathrm{O} \\
& \mathrm{Zn}\left(\mathrm{NO}_{3}\right)_{2} \cdot 6 \mathrm{H}_{2} \mathrm{O}+\mathrm{Ca}\left(\mathrm{NO}_{3}\right)_{2} \cdot 4 \mathrm{H}_{2} \mathrm{O}+\mathrm{H}_{3} \mathrm{PO}_{4} \rightarrow \mathrm{CaZnHPO}_{4}+ \\
& 2\left(\mathrm{HNO}_{3}\right)_{2}+10 \mathrm{H}_{2} \mathrm{O}
\end{aligned}
$$

Figure 1a \& b shows the photograph of Pure and Calcium doped $\mathrm{ZnHPO}_{4}$ crystals grown in the silica gel medium. Calcium ions diffuse through the gel and a thin white film in the form of a ring appeared known as Liesegang ring [14]. Figure 2 shows a different type of morphology of Pure and Calcium doped $\mathrm{ZnHPO}_{4}$ grown crystals.

\subsection{Characterization}

Surface Enhanced Raman spectra were recorded using Laser Raman spectrometer (Renishaw Invia) with laser excitation lines of 488 and $514 \mathrm{~nm}$ respectively at room temperature with power of $15 \mathrm{~mW}$ and acquisition of 6 seconds applied for the individual samples. The thermal behavior of the crystal was characterized using thermo gravimetric analysis (TGA) and differential thermo gravimetric (DTA) analysis by Perkin Elmer STA 6000 thermal analyzer. A platinum crucible was used for heating the sample and analyses were carried out in nitrogen atmosphere at a heating rate of $20^{\circ} \mathrm{C} / \mathrm{min}$ in the temperature range $30^{\circ} \mathrm{C}$ to $700^{\circ} \mathrm{C}$. EDAX (FEI-Quanta 250) was used for the analysis of determine the chemical composition of the elements present in the material. In the present investigation, the photoluminescence spectra of samples were recorded with Cary Eclise WinFLR photoluminescence devices.

\section{RESULTS AND DISCUSSION}

\subsection{Laser Raman Spectral Analysis}

The recorded Raman spectrum of pure and calcium doped zinc hydrogen phosphate is shown in Figure 3. Laser Raman analyses created a big impact in scientific technique which is widely used to identify the functional units, internal structure of molecules and chemical bonds of a compound. Raman spectroscopy is widely used for receiving information about different modes in crystals. Figure 3 shows the Raman spectrum for the pure $\mathrm{ZnHPO}_{4}$ and $\mathrm{Ca}$ doped $\mathrm{ZnHPO}_{4}$ crystals. The Raman spectra exhibits good band splits with clearly resolved bands. The intensity was very low compared to the other lines obtained for both samples at $176 \mathrm{~cm}^{-1}$ where there is metal-metal stretching mode. The absorption bands at $312 \mathrm{~cm}^{-1}$ were attributed to $\mathrm{P}-\mathrm{O}$ bending vibration, respectively. The intensity of the band is observed in the Raman spectrum at $941 \mathrm{~cm}^{-1}$ and is assigned to the $\mathrm{v}_{\mathrm{s}}\left(\mathrm{PO}_{4}\right)$ symmetric stretching mode. Other Raman bands are obtained at 1150,1059, 1000 and $995 \mathrm{~cm}^{-1}$ and are assigned to the $\mathrm{v}_{\mathrm{as}}\left(\mathrm{PO}_{4}\right)$ antisymmetric stretching modes [15]. 

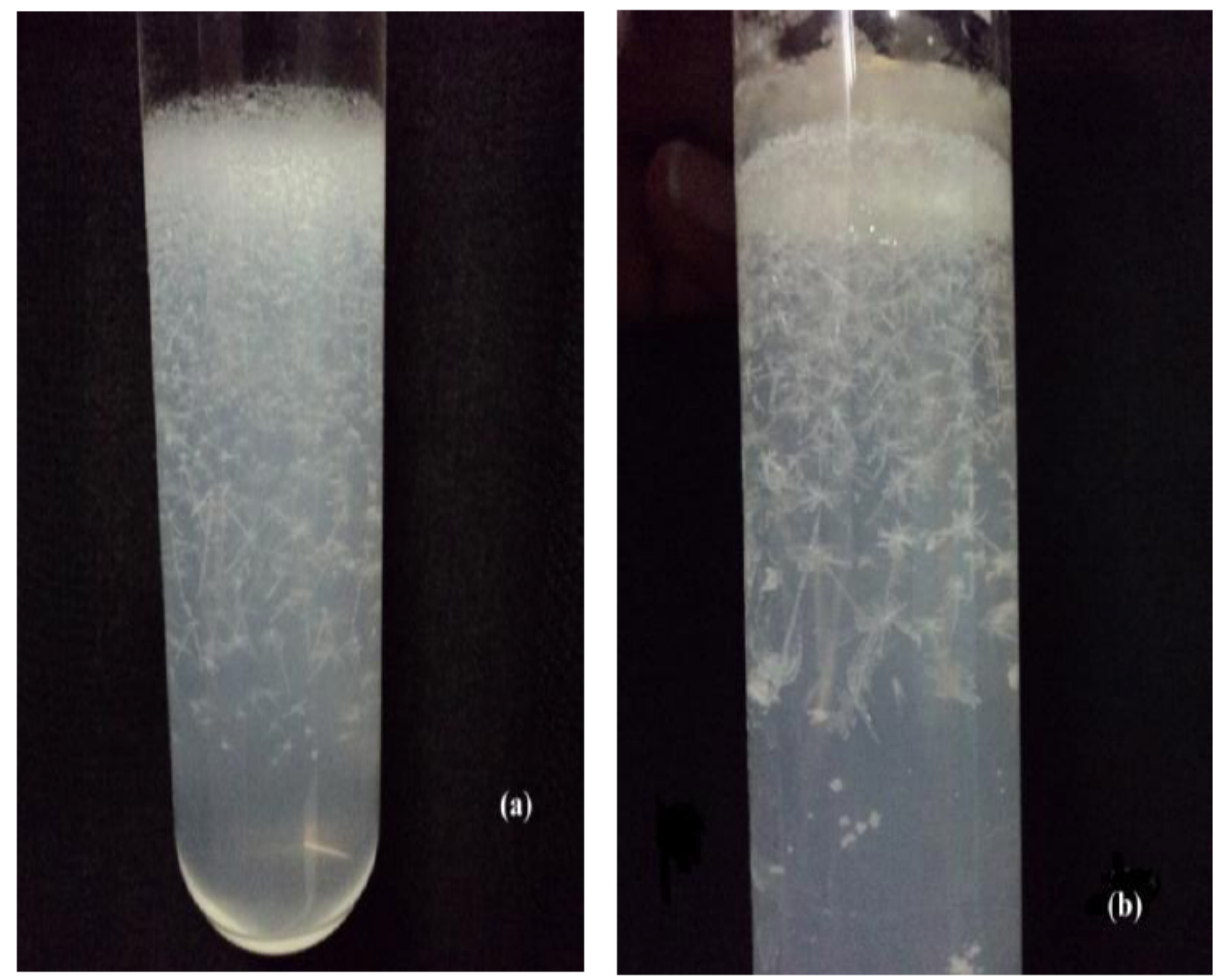

Figure 1: (a) Pure $\mathrm{ZnHPO}_{4}$ crystals grown in gel medium, (b) Liesegang ring observed for $6.0 \mathrm{pH}$ value and supernatant concentration of $1 \mathrm{~N}$ calcium doped $\mathrm{ZnHPO}_{4}$ crystals.
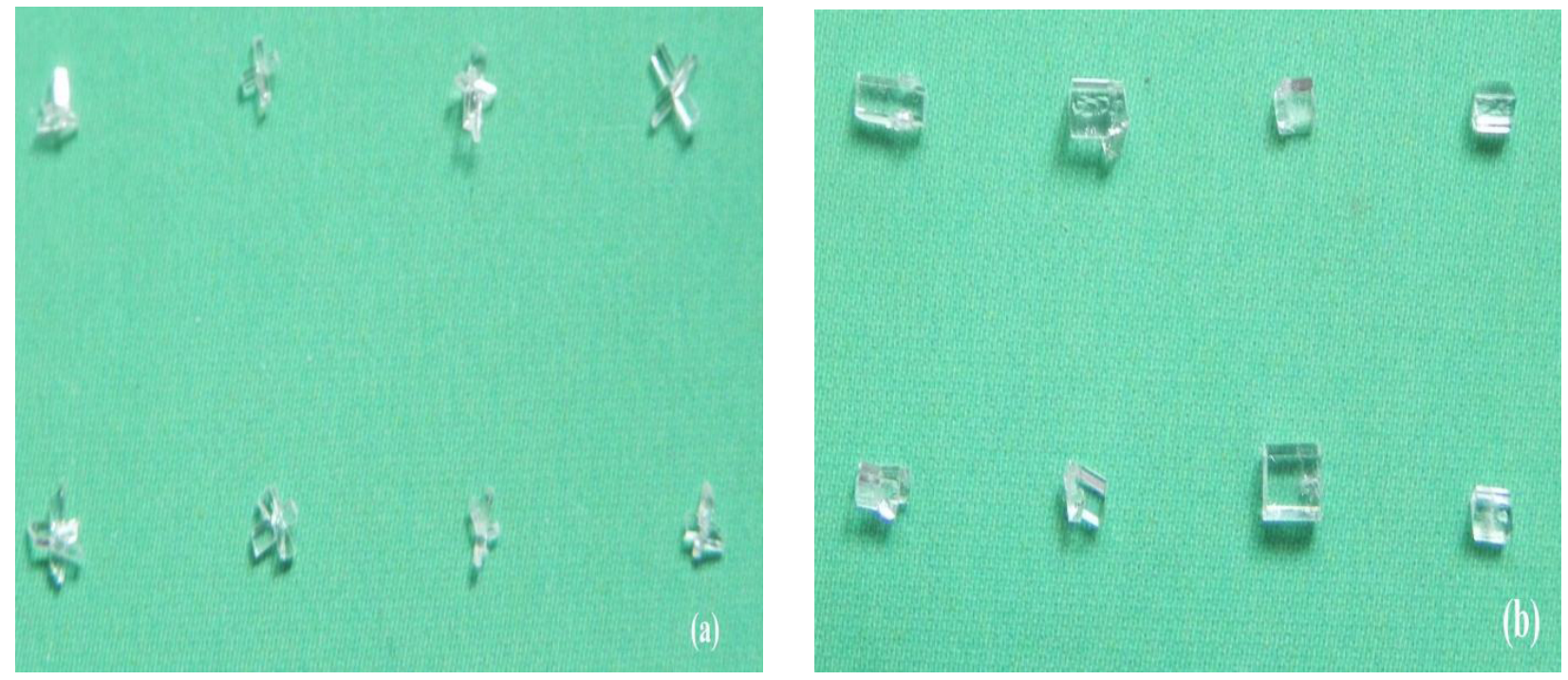

Figure 2: (a) \& (b) Different morphology of Pure and calcium doped $\mathrm{ZnHPO}_{4}$ crystals.

\subsection{TG/DTA Studies of $\mathrm{ZnHPO}_{4}$ and $\mathrm{Ca}$ Doped $\mathrm{ZnHPO}_{4}$ Crystals}

Thermal gravimetric analysis (TG) sets the task of providing a quantitative measurement of any weight changes connected with thermally induced transitions and in the differential thermal analysis (DTA), the difference in the temperature between the levels and the thermally inert reference material is measured as a function of temperature. The samples (pure $\mathrm{ZnHPO}_{4}$ and $\mathrm{Ca}$ doped $\mathrm{ZnHPO}_{4}$ ) was scanned the rate of $20^{\circ} \mathrm{C} /$ minute in nitrogen atmosphere in the temperature range $30^{\circ} \mathrm{C}$ to $700^{\circ} \mathrm{C}$. The thermal behavior of pure $\mathrm{ZnHPO}_{4}$ and $\mathrm{Ca}$ doped $\mathrm{ZnHPO}_{4}$ are shown in Figure $4 \mathbf{a} \& \mathbf{b}$. From the TG curve of pure $\mathrm{ZnHPO}_{4}$ and $\mathrm{Ca}$ doped $\mathrm{ZnHPO}_{4}$ are thermally stable upto $71^{\circ} \mathrm{C}$ and $88^{\circ} \mathrm{C}$ respectively. The first stage of decomposition in the case of pure $\mathrm{ZnHPO}_{4}$ start from $71^{\circ} \mathrm{C}$ and continues upto $123^{\circ} \mathrm{C}$ resulting in weight loss of about $11.4 \%$ which indicates endothermic dehydration and decomposition of the material by liberation of three water molecules. The second stage of decomposition starts from $123^{\circ} \mathrm{C}$ to $246^{\circ} \mathrm{C}$ resulting in weight loss of about $9 \%$. This 
weight loss in the second stage of decomposition corresponds to the elimination of three water molecules. The third stage of decomposition starts from $246^{\circ} \mathrm{C}$ and goes upto $310^{\circ} \mathrm{C}$ leading to weight loss of $10 \%$ and form anhydrous pure $\mathrm{ZnHPO}_{4}$ to $\mathrm{ZnO}$. However it is decomposed in the temperature interval $310-512^{\circ} \mathrm{C}$, and forms a residue. Table $3 a$ gives the compiled summary of the decomposition process of $\mathrm{ZnHPO}_{4} \cdot 6 \mathrm{H}_{2} \mathrm{O}$. It can be seen that the calculated weight loss is in close proximity with the observed values.

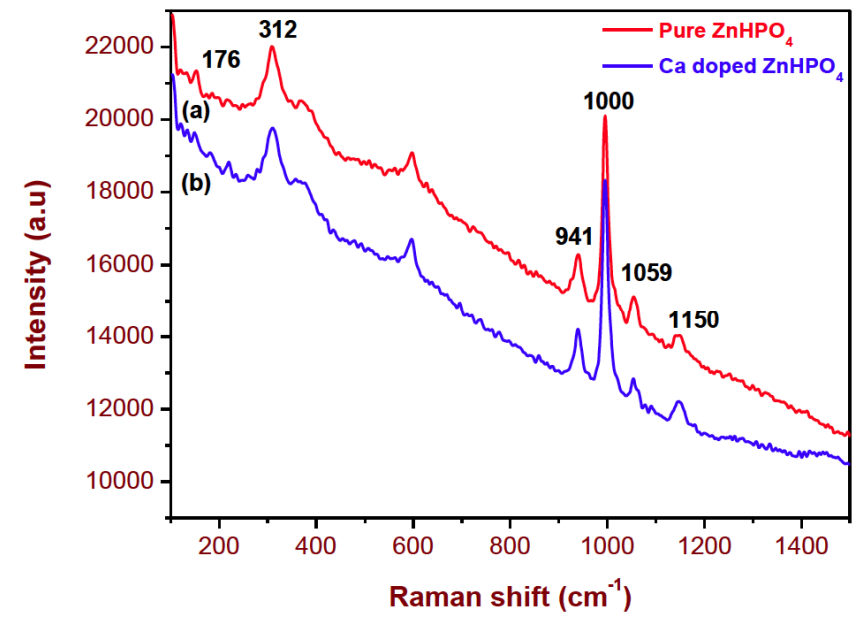

Figure 3: Laser Raman spectrum of $\mathrm{ZnHPO}_{4}$ and $\mathrm{Ca}$ doped $\mathrm{ZnHPO}_{4}$ crystals.

From the thermogram of $\mathrm{Ca}$ doped $\mathrm{ZnHPO}_{4}$ (Figure $4 \mathbf{b}$ ), it is clear that the doped material is thermally stable up to temperature of $88^{\circ} \mathrm{C}$, which means that doped material is more stable than pure one. Similarly, in the case of Ca doped $\mathrm{ZnHPO}_{4}$ the first stage of decomposition starts from $88^{\circ} \mathrm{C}$ and continues upto $153^{\circ} \mathrm{C}$ resulting in weight loss of about $19.11 \%$. This indicates that the removal of four water molecules attached to the doped system gets decomposed. The second stage of decomposition starts from $123^{\circ} \mathrm{C}$ and goes upto $306^{\circ} \mathrm{C}$ leading to weight loss of $18 \%$. The weight loss in the second stage of decomposition corresponds to the conversion of anhydrous $\mathrm{CaZnHPO}_{4}$ to CaZnO. Table $\mathbf{3 b}$ gives detailed summary of the decomposition of $\mathrm{CaZnHPO}_{4} \cdot 4 \mathrm{H}_{2} \mathrm{O}$ along with calculated weight losses. It is worth mentioning here that the temperature for the formation of stable product after decomposition in case of pure one is $312^{\circ} \mathrm{C}$, whereas in case of doped one the stable product is formed at a temperature of $307^{\circ} \mathrm{C}$. This means that the temperature for the formation of end product decreases with calcium substitution.

As seen from DTA curve in case of pure $\mathrm{ZnHPO}_{4}$ (Figure 4a) and $\mathrm{Ca} \mathrm{ZnHPO}_{4}$ (Figure 4b) there is well marked endothermic peak and exothermic decomposition. Since peaks in DTA curve correspond to weight loss in TG curve thereby suggesting some structural changes taking place in the material apart from weight loss in the material. The availability of these peaks can be explained in terms of energy requirements. The energy of peaks does not necessarily depend only on the amount of water loss on dehydration but also depends on the structural factors. Table 4 gives the compiled summary of the data of DTA of pure $\mathrm{ZnHPO}_{4}$. The DTA plot exhibits a smooth endotherm at 123 , 158 and $296^{\circ} \mathrm{C}$. These values correspond to the thermal decomposition process in the ranges 71-123, 190-240 and 246-310 ${ }^{\circ} \mathrm{C}$, respectively. The sharpness of endothermic peaks shows a good degree of crystallinity and purity of the sample. The decomposition process agrees fairly well with pure $\mathrm{ZnHPO}_{4}$. Table 5 also gives detailed summary of the data of DTA of $\mathrm{Ca}$ doped $\mathrm{ZnHPO}_{4}$. DTA plot exhibits a smooth endotherm at 122,220 and $294^{\circ} \mathrm{C}$. These values correspond to the thermal decomposition process in the ranges $88-123,123-224$ and $224-306^{\circ} \mathrm{C}$, respectively. It agrees with $\mathrm{Ca}$ doped $\mathrm{ZnHPO}_{4}$.

From the thermal analysis of the system confirmed that product formed in the pure form, that is, $\mathrm{ZnHPO}_{4}$ is associated with six water molecules having composition $\mathrm{ZnHPO}_{4} \cdot 6 \mathrm{H}_{2} \mathrm{O}$, whereas the doped one that is, $\mathrm{Ca}$ doped $\mathrm{ZnHPO}_{4}$, is associated with four water molecules having

Table 3: (a) Results of Thermal Decomposition for Different Temperature Ranges with Calculated Weight Loss in Case of Pure $\mathrm{ZnHPO}_{4}$

\begin{tabular}{|c|c|c|c|}
\hline Stage & Temperature $\left({ }^{\circ} \mathrm{C}\right)$ & Decomposition Steps & Weight loss (\%) \\
\hline \hline First & $71-123$ & $\mathrm{ZnHPO}_{4} \cdot 6 \mathrm{H}_{2} \mathrm{O} \rightarrow \mathrm{ZnHPO}_{4} \cdot 3 \mathrm{H}_{2} \mathrm{O}+3 \mathrm{H}_{2} \mathrm{O}$ & 11.4 \\
\hline Second & $123-246$ & $\mathrm{ZnHPO}_{4} \cdot 3 \mathrm{H}_{2} \mathrm{O} \rightarrow \mathrm{ZnHPO}_{4}+3 \mathrm{H}_{2} \mathrm{O}$ & 19 \\
\hline Third & $246-310$ & $2 \mathrm{ZnHPO}_{4} \rightarrow 2 \mathrm{ZnO}+\mathrm{P}_{2} \mathrm{O}_{5}+\mathrm{H}_{2} \mathrm{O}$ & 10 \\
\hline
\end{tabular}

Table 3: (b) Results of Thermal Decomposition for Different Temperature Ranges with Calculated Weight Loss in Case of Ca Doped $\mathrm{ZnHPO}_{4}$

\begin{tabular}{|c|c|c|c|}
\hline Stage & Temperature $\left({ }^{\circ} \mathrm{C}\right)$ & Decomposition Steps & Weight loss $(\%)$ \\
\hline \hline First & $88-123$ & $\mathrm{CaZnHPO}_{4} \cdot 4 \mathrm{H}_{2} \mathrm{O} \rightarrow \mathrm{CaZnHPO}+4 \mathrm{H}_{2} \mathrm{O}$ & 19.1 \\
\hline Second & $123-306$ & $2 \mathrm{CaZnHPO}{ }_{4} \rightarrow 2 \mathrm{CaZnO}+\mathrm{P}_{2} \mathrm{O}_{5}+\mathrm{H}_{2} \mathrm{O}_{(\mathrm{g})}$ & 18 \\
\hline
\end{tabular}



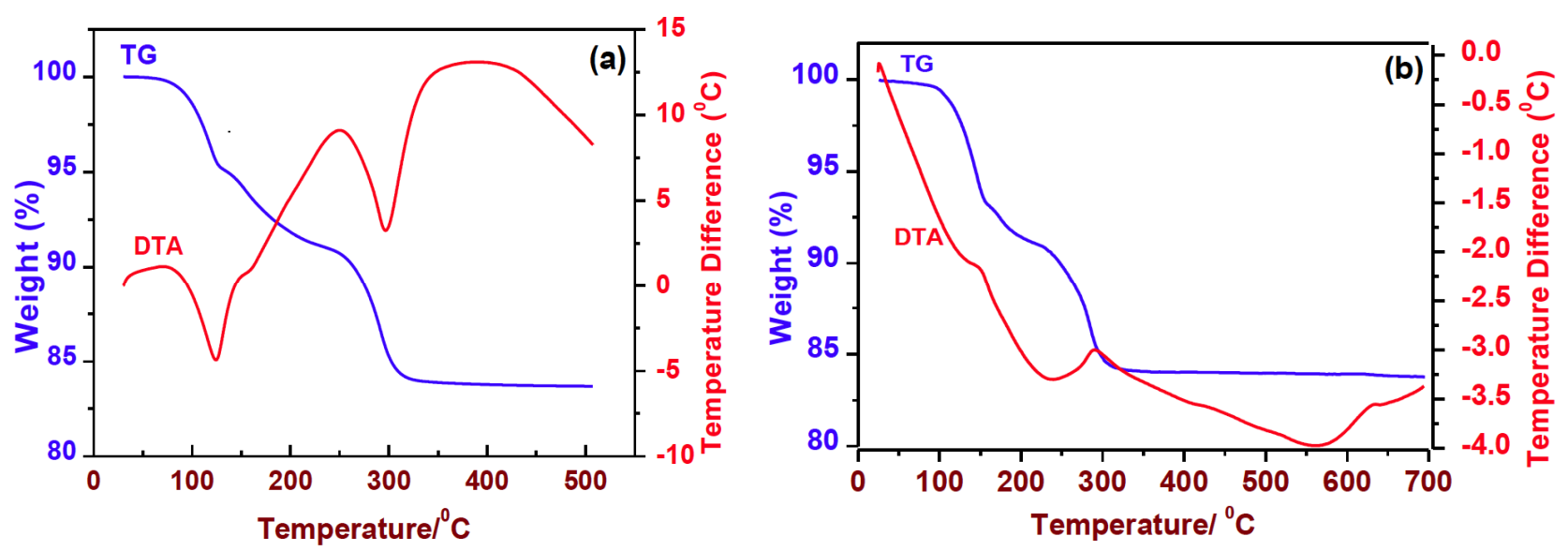

Figure 4: (a) Thermogram of TGA and DTA curves for pure $\mathrm{ZnHPO}_{4}$. (b) Thermogram of TGA and DTA curves for Calcium doped ZnHPO

Table 4: $\quad$ DTA Data of Pure $\mathrm{ZnHPO}_{4}$ Crystal

\begin{tabular}{|c|c|c|c|}
\hline Peak recorded & Peak height & Nature & On set temperature \\
\hline \hline $123^{\circ} \mathrm{C}$ & -4.5 & Endothermic & $124^{\circ} \mathrm{C}$ \\
\hline $158^{\circ} \mathrm{C}$ & 0.5 & Endothermic & $157^{\circ} \mathrm{C}$ \\
\hline $296^{\circ} \mathrm{C}$ & 3.3 & Exothermic & $295^{\circ} \mathrm{C}$ \\
\hline
\end{tabular}

Table 5: DTA Data of Ca Doped $\mathrm{ZnHPO}_{4}$ Crystal

\begin{tabular}{|c|c|c|c|}
\hline Peak recorded & Peak height & Nature & On set temperature \\
\hline \hline $122^{\circ} \mathrm{C}$ & -1.9 & Endothermic & $123^{\circ} \mathrm{C}$ \\
\hline $292^{\circ} \mathrm{C}$ & -3.0 & Exothermic & $290^{\circ} \mathrm{C}$ \\
\hline
\end{tabular}

composition $\mathrm{Ca}$ doped $\mathrm{ZnHPO}_{4} \cdot 4 \mathrm{H}_{2} \mathrm{O}$. These compositions were further supported by other analysis like energy dispersive X-ray analysis (EDAX).

\subsection{Energy Dispersive Analysis of $\mathrm{ZnHPO}_{4}$ and $\mathrm{Ca}$ Doped $\mathrm{ZnHPO}_{4}$ Crystals}

To study the elemental composition of pure $\mathrm{ZnHPO}_{4}$ and $\mathrm{Ca}$ doped $\mathrm{ZnHPO}_{4}$, qualitative and quantitative analysis were performed by energy dispersive X-ray analysis. The spectrum observed from EDAX analysis is shown in Figure $\mathbf{5 a}$ and $\mathbf{5 b}$. EDAX pattern shows peaks related to all the major elements present in the developed crystals as should be expected from pure $\mathrm{ZnHPO}_{4}$ system. The spectra corresponding to Calcium doped $\mathrm{ZnHPO}_{4}$ shows peaks corresponding to all the major elements, that is, zinc, phosphorous and oxygen along with calcium by suggesting that $\mathrm{Ca}^{2+}$ has entered into the lattice of $\mathrm{ZnHPO}_{4}$ system. Anyhow, in addition to this no impurities of elements were identified. In pure $\mathrm{ZnHPO}_{4}$, the zinc to phosphorus $(Z n / P)$ ratio was found to be 1.94 . In calcium doped $\mathrm{ZnHPO}_{4}$, $(\mathrm{Ca}+\mathrm{Zn}) / \mathrm{P}$ ratio was estimated to be 1.90 . The experimental calculated atomic and weight percentages of the individual elements are shown in Table $\mathbf{6 a}$ and $\mathbf{6 b}$. It can be noticed that the presence of zinc leads to the ' $\mathrm{Ca}$ ' reduction when compared to pure system. However, it is important to mention here that EDAX analysis does not give experimental values of atomic and weight percentage for lighter elements like hydrogen. The presence of $\mathrm{H}_{2} \mathrm{O}$ molecules in $\mathrm{ZnHPO}_{4}$ and $\mathrm{Ca}$ doped $\mathrm{ZnHPO}_{4}$ was further confirmed by thermo analytical analysis.

\subsection{Photoluminescence Analysis}

The Photoluminescence spectroscopy is a contactless, nondestructive method of exploring the electronic structure of materials. Also the Photoluminescence $(\mathrm{PL})$ measurements can be used as a effective and sensitive tool to observe the effects of purification and contamination during crystal growth process [16]. The room-temperature photoluminescence excitation and emission spectra of pure and calcium doped zinc hydrogen phosphate are presented in Figure $6 \mathbf{a}$ \& $\mathbf{b}$ respectively. It exhibits the characteristic excitation and emission peaks of the samples and the electronic transitions for all of the observed emission peaks. The emission spectrum displays the four important peaks for pure ZHP is mainly at 305, 376, 403 and $467 \mathrm{~nm}$ when excited with 270 $\mathrm{nm}$. Of these, the ultra violet emission at $305 \mathrm{~nm}$ is the most intense of all emissions. For Calcium doped ZHP emission spectrum signifies the peaks at 306, 376, 405 and $468 \mathrm{~nm}$ when excited with $270 \mathrm{~nm}$. Apart from these emissions, the 


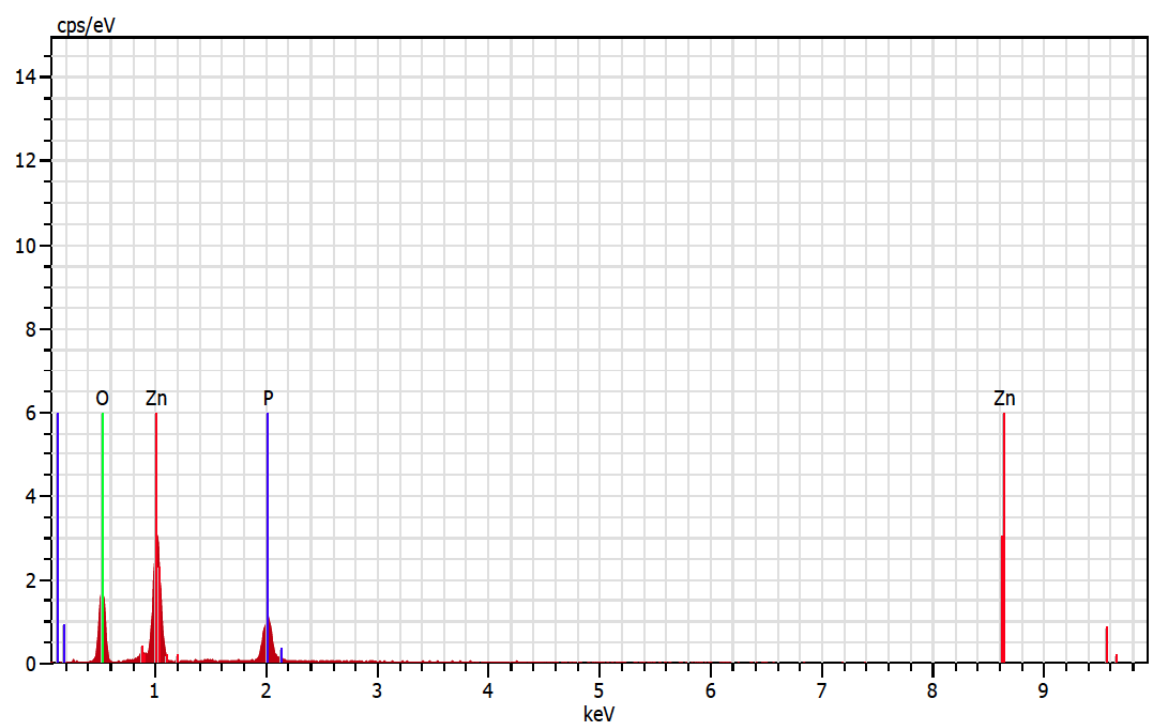

(a)

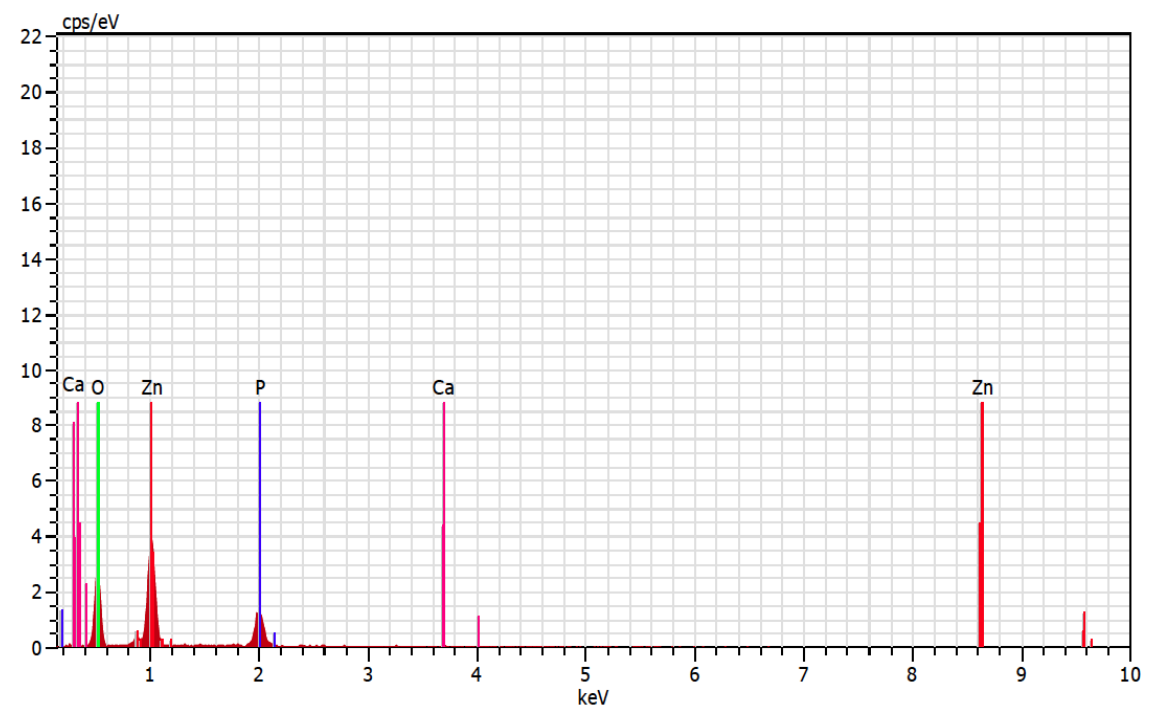

(b)

Figure 5: (a) Energy dispersive X-ray analysis (EDAX) spectrum revealing the presence of major elements for pure $\mathrm{ZnHPO}_{4}$ crystal. $(\mathbf{b})$ Energy dispersive X-ray analysis (EDAX) spectrum revealing the presence of major elements for calcium doped $\mathrm{ZnHPO}$.

Tables 6: (a) Experimental Calculated Compositions Obtained from Energy Dispersive X-Ray Analysis (EDAX) of Various Constituent Elements Present in Case of Pure $\mathrm{ZnHPO}_{4}$ Crystal

\begin{tabular}{|c|c|c|}
\hline Element & Weight \% & Atomic \% \\
\hline \hline $\mathrm{Zn}$ & 53.33 & 24.42 \\
\hline $\mathrm{P}$ & 13.01 & 12.58 \\
\hline $\mathrm{O}$ & 33.66 & 63 \\
\hline
\end{tabular}

Tables 6: (b) Experimental Calculated Compositions Obtained from Energy Dispersive X-Ray Analysis (EDAX) of Various Constituent Elements Present in Case of Calcium Doped $\mathrm{ZnHPO}_{4}$

\begin{tabular}{|c|c|c|}
\hline Element & Weight \% & Atomic \% \\
\hline \hline Zn & 50.62 & 22.36 \\
\hline $\mathrm{P}$ & 12.72 & 11.86 \\
\hline $\mathrm{Ca}$ & 0.37 & 0.27 \\
\hline $\mathrm{O}$ & 36.29 & 65.51 \\
\hline
\end{tabular}




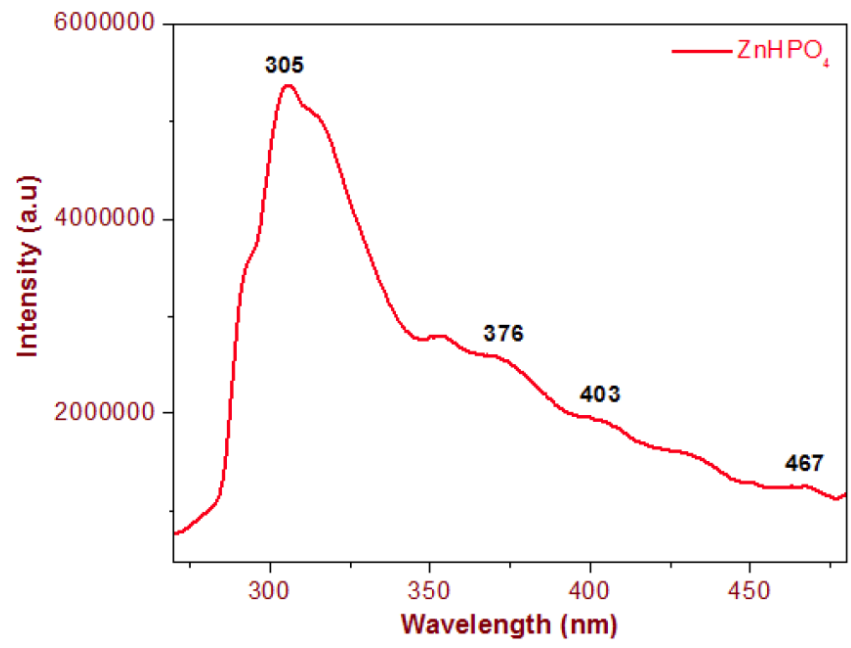

(a)

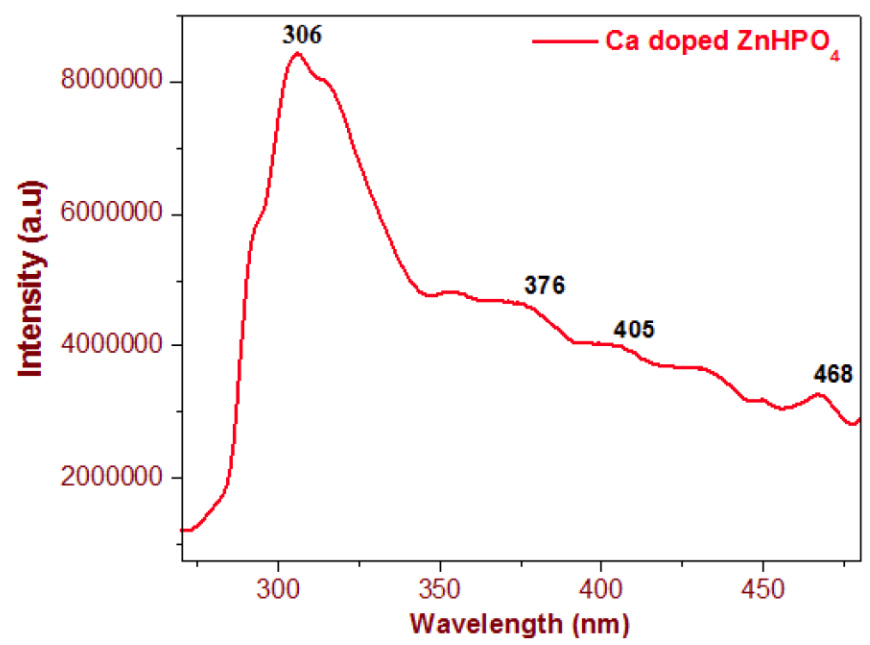

(b)

Figure 6: (a) Photoluminescence spectrum of pure ZHP crystal. (b) Photoluminescence spectrum of Calcium doped ZHP crystal.

ultra violet emission at $306 \mathrm{~nm}$ is the most intense of all emissions. The little different PL intensities of the samples show a slight variation of sample thickness. The variation of sample thickness is quiet random and it has no direct correlation with Calcium doping. The photoluminescence spectra of the sample pure and calcium doped ZHP is received with the excitation wavelength and broad band centered at $305 \mathrm{~nm}$ and $306 \mathrm{~nm}$ respectively. The sample exhibits an emission within the ultraviolet region. Peaks are observed to shift towards blue region as the particle size decreases. Using the photoluminescence spectrum band gap will be calculated using the formula.

$$
\mathrm{E}_{\mathrm{g}}=\mathrm{hv}
$$

Where,

$$
\begin{aligned}
& E_{g}=\text { band gap energy } \\
& h=\text { Planks constant }\left(6.625 \times 10^{-34} \mathrm{Js}\right) \\
& v v=\mathrm{C} / \lambda \\
& \mathrm{C}=\text { velocity of light }\left(3 \times 10^{8} \mathrm{~m} / \mathrm{s}\right)
\end{aligned}
$$

The curve can be observed for pure and calcium doped zinc hydrogen phosphate crystal at $305 \mathrm{~nm}$ and $306 \mathrm{~nm}$ implying the band gap $\mathrm{E}_{\mathrm{g}}$ is $4.072 \mathrm{eV}$ and $4.059 \mathrm{eV}$ respectively.

\section{CONCLUSION}

Synthesis of pure zinc hydrogen phosphate $\left(\mathrm{ZnHPO}_{4}\right)$ and calcium doped $\mathrm{ZnHPO}_{4}$ crystals in the form of single crystal were achieved by single diffusion technique at room temperature. The impact of various gel parameters such as the density, $\mathrm{pH}$ and age of the gel, concentration of the reactants, etc. were changed to minimize the nucleation density. The variations of the nucleation density with all these parameters are extensive. The presence of various functional groups or chemical bonds in molecules was confirmed by the
Laser Raman spectroscopy. The thermal studies suggest that pure $\mathrm{ZnHPO}_{4}$ is stable up to temperature of $71^{\circ} \mathrm{C}$ whereas calcium doped $\mathrm{ZnHPO}_{4}$ is stable up to a temperature of $88^{\circ} \mathrm{C}$. In this process, the doping of Calcium increases their thermal stability. Also, temperature for the formation of end product decreases with calcium substitution. The chemical composition of pure and Calcium doped Zinc hydrogen phosphate crystal was determined by EDAX analyses. Photoluminescence emission peaks can be observed for pure and calcium doped zinc hydrogen phosphate crystals at $305 \mathrm{~nm}$ and $306 \mathrm{~nm}$ implying the band gap $E_{\mathrm{g}}$ is $4.072 \mathrm{eV}$ and $4.059 \mathrm{eV}$ respectively.

\section{REFERENCES}

[1] Henisch HK, Dennis J, Hanoka JI. Crystal growth in gels. J Phys Chem Solids 1965; 26: 493. https://doi.org/10.1016/0022-3697(65)90123-X

[2] Henisch HK. Crystal Growth in Gells, Pennsylvania State University Press, University Park, Pennsylvania, 1970.

[3] Dharma Prakash SM, Mohan Rao P. Periodic crystallization of barium oxalate in silica hydrogel. Bull Mater Sci 1986; 4: 511-517. https://doi.org/10.1007/BF02744117

[4] Shedam MR, Venkateswara Rao. Nucleation and growth of CdC2O4-3H2O single crystals in silica gels. Bull Mater Sci 1993; 16: 309-315.

https://doi.org/10.1007/BF02746041

[5] Garud SL, Saraf KB. Growth and study of mixed crystals of Ca-Cd iodate. Bull Mater Sci 2008; 31: 639-643. https://doi.org/10.1007/s12034-008-0102-5

[6] Joshi MS, Mohan Rao P, Antony AV. Growth of single crystals of some complex salts in silica gels. Bull Mater Sci 1980; 2: 127. https://doi.org/10.1007/BF02743984

[7] Dharma Prakash SM, Mohan Rao P. Growth of CdxBa1-xC2O4 mixed crystals in silica hydrogel. J Mater Sci Lett 1986; 5: 769. https://doi.org/10.1007/BF01730085

[8] Justin Raj C, Mangalam G, Mary Navis Priya S, Mary Linet J, Vesta C, Dinakaran S, Milton Boaz B, Jerome Das S. Growth and characterization of nonlinear optical zinc hydrogen phosphate single crystal grown in silica gel. Crystal Research Technology 2007; 42(4): 344.

https://doi.org/10.1002/crat.200610826

[9] Suresh Kumar B, Rahim Kutt MHY, Sudarsana Kumar MR, Rajendra Babu K. Growth and characterization of pure and lithium doped strontium tartrate tetrahydrate crystals by solution-gel technique. Bulletin of Material Science 2007; 30(4): 349. https://doi.org/10.1007/s12034-007-0058-x 
[10] Girase KD Girase ND, Sawant DK, Patil HM, Bhavsar DS, Advances in Applied Science Research 2011; 2(4): 233

[11] Kalainathan S, Nisha Santha Kumari P. Comparative study of pure and alkaline earth metallic doped cadmium mercury thiocyanate single crystals-Gel technique. Spectrochimica Acta Part A, Molecular and Biomolecular Spectroscopy 2009; 73: 127. https://doi.org/10.1016/i.saa.2009.02.005

[12] Jagdish P, Rajesh NP. Effect of copper on the growth morphology and characterization of zinc mercury thiocyanate crystals. Journal of Industrial and Engineering Chemistry 2012; 18(6): 2157. https://doi.org/10.1016/i.jiec.2012.06.012

[13] Binitha MP, Pradyumnan PP. Studies on growth, thermal and dielectric behavior of calcium succinate trihydrate single crystals. Journal of Crystal Growth 2014; 396: 38. https://doi.org/10.1016/i.jcrysgro.2014.03.033
[14] Julyan Cartwright HE, Juan Manuel Garcia-Ruiz, Ana I. Villacampa, Computer Physics Communications 1999; 121: 411.

[15] Pawlig O, Trettin R. Synthesis and characterization of $\alpha$-hopeite, Zn3(PO4)2·4H2O. Mater Res Bull 1999; 34: 1959. https://doi.org/10.1016/S0025-5408(99)00206-8

[16] Zajac MJ, Gosk E, Grzanka S, Palczewska SM, Wysmołek A, Korona K, Kami'nska M, Twardowski A. Ammonothermal synthesis of GaN doped with transition metal ions (Mn, Fe, Cr). J Alloys Comp 2008; 456: 324-338

https://doi.org/10.1016/i.jallcom.2007.02.046 